\title{
Higher Education and the Opportunities and Challenges of Educational Technology
}

\author{
Stefan Strecker • Dennis Kundisch • Franz Lehner • \\ Jan Marco Leimeister $\cdot$ Petra Schubert
}

Published online: 25 January 2018

(C) Springer Fachmedien Wiesbaden GmbH, part of Springer Nature 2018

\section{Introduction}

Present educational technology creates a multitude of options for designing and delivering higher education courses - finding a proper set-up of teaching strategies and corresponding teaching and learning tools, i.e., interlinking them purposefully and meaningfully, however, presents a profound challenge to course instructors when (re-)designing their courses.

Examples of technology-driven innovations in teaching higher education courses include the use of mobile and video technology in teaching strategies such as the inverted/flipped classroom and the use of collaboration technology in so-called 'blended learning' approaches which mix different modes of interaction between instructor and students, e.g., virtual and classroom interaction. Obviously, the students' learning experience is readily enhanced by

Prof. Dr. S. Strecker $(\bowtie)$

Enterprise Modelling Research Group, Chair of Information

Systems Development, University of Hagen, Universitätsstraße

41, 58097 Hagen, Germany

e-mail: stefan.strecker@fernuni-hagen.de

Prof. Dr. D. Kundisch

Paderborn University, Paderborn, Germany

Prof. Dr. F. Lehner

University of Passau, Passau, Germany

Prof. Dr. J. M. Leimeister

University of St. Gallen, St. Gallen, Switzerland

Prof. Dr. J. M. Leimeister

University of Kassel, Kassel, Germany

Prof. Dr. P. Schubert

University of Koblenz-Landau, Koblenz, Germany abundant online resources including educational videos on virtually every topic - and level of usefulness (whether guided by the course instructor or not).

However, seizing these technology-enabled opportunities when (re-)designing a course has shown to lead to an intricate design problem for which even defining an overall design objective is discussed as challenging (if student success is such a design objective, how is it operationalized and measured?). In a recent essay, Werbach exemplifies these challenges in - what he calls - a 'failure narrative' reporting on the development of a course over a 4 year period with flipped and other technology-enhanced settings which lead to constant low student evaluations and inconsistent student feedback (Werbach 2016).

Based on the assumption that more experience reports discussing 'failure' and 'success' will help us better understand how to seize the potentialities of 21 st century technology for higher education teaching, we have invited four discussants who have experimented with innovative educational technology in different ways and course settings, and have asked them about their teaching experiences and the feedback they received from participating students. We suggested the following guiding questions to the discussants:

- What was your teaching innovation? What did you change compared to your earlier teaching approach?

- What did you perceive as main challenges with implementing the new course design? Did you use any support from instructional designers or did you approach the problem on your own?

- What did work well and why? What did not work well and why?

- Did you stay with your new teaching approach? What did you modify? 
- Do you have any advice for other course instructors? Any lessons learned? What blend of strategies and tools did suit your purposes?

- Did you use a textbook in addition to educational technology? Do you consider textbooks are out of date? Will audio and/or visual material take over?

Prof. Dr. Stefan Strecker University of Hagen

\section{Developing and Using an Audience Response System}

\subsection{What was Your Teaching Innovation?}

It is well established in the literature that active participation vitalizes and supports a student's learning process. One way of fostering participation in lectures is through didactical designs that stimulate cooperative activities among students using audience response systems (ARS). An ARS is an IT-enabled system typically used in face-toface settings that enables polling students and gathering immediate feedback in response to questions posed by instructors. The usage of ARS for educational purposes started back in the $1950 \mathrm{~s}$, and commercialized products have been available since the 1990s. These products typically require a set of physical clickers distributed among the students, a radio-frequency connection device linked to the instructor's laptop, and software installed on the latter. Instructors (including myself) have found these ARS products cumbersome to use, both in terms of the software and of the management of clickers in the classroom, especially in larger lectures.

Having been responsible for a course with about 1200 students in the winter term 2011/2012 at Paderborn University, we started developing the ARS PINGO (Peer Instruction for very large groups) in spring 2011 as software-as-a-service, ${ }^{1}$ and have made it available free of charge to anybody worldwide. PINGO allows to simultaneously and anonymously poll an arbitrary number of students using Internet-enabled devices (laptops, tablets, smartphones etc.). Our primary focus for the development of this web application was ease of use. This focus resulted in a low-threshold product that, at the time of writing (November 2017), is being used by over 14,500 instructors worldwide.

Although PINGO is - or at the time of its development, was - a technological rather than a teaching innovation, the

\footnotetext{
${ }^{1}$ Information about the PINGO artifact and the ARS market in general can be found in Kundisch et al. (2012, 2013a, b). More information on PINGO is also available at http://trypingo.com/ and http://www.upb.de/pingo. PINGO's source code is also shared via GitHub (https://github.com/PingoUPB).
}

new technology facilitates a wide range of sophisticated teaching approaches, compared to the status quo in 2011. The greater choice of question formats available with PINGO - e.g., single-choice, multiple-choice, free text questions, questions with number-response - can be used to support established teaching approaches such as Peer Instruction (Mazur 1997), Class-wide Discussions (Dufresne et al. 1996), and Optional Course Discussion (Beutner et al. 2014). Other useful applications for PINGO include: training for multiple choice exams in class, recapping content from the last lecture, introducing new content through linking questions, assessing comprehension, or simply capturing instant feedback on a presentation or lecture.

\subsection{What Did You Change Compared to Your Earlier Teaching Approach?}

Unsurprisingly, I make greater use of an ARS (i.e., PINGO) in my lectures. Developing PINGO made me aware of other tools and possible usage interactions with PINGO (e.g., functionalities in Moodle or ILIAS) which in turn prompted me to read up on and reflect about the use of technology in teaching, and teaching and learning theory more generally. As a result, my toolset of didactical designs was enriched, which I expect to also benefit my students.

\subsection{What Did You Perceive as Main Challenges} with Implementing the New Course Design?

First, when PINGO is used to pose questions to inspire students to reflect about a subject matter, the most challenging part is to develop good questions. Such questions should not focus on knowledge and recall but help unveil students' misconceptions (check their understanding rather than retention of facts). This is challenging, in particular when using single- or multiple-choice questions. In my own experience, few test banks that come with standard textbooks are very helpful in this sense. Second, while I was heavily involved in the development of PINGO, I found myself focusing my course design more on the new technology and the didactical options it offered, and less on the intended learning outcomes. Third, implementing a new or at least an augmented course design turned out to be far more time-consuming than I had anticipated.

\subsection{Did You Use Any Support from Instructional Designers or Did You Approach the Problem on Your Own?}

As the development of PINGO was a joint effort with colleagues from Didactics of Informatics, Business and 
Human Resource Education, and Chemistry, we benefited not only from robust technological and didactical/pedagogical competencies but also from many years of experience of traditional clicker usage in our team.

\subsection{What Did Work Well and Why?}

The steady flow of about 100 new registered PINGO instructors per week on average - without undertaking any substantial marketing efforts - may be taken as evidence that the PINGO technology has been very well received, and that it works well both for instructors as well as students. In addition, evaluations from my own students show how much PINGO is appreciated, in particular when it is applied as an exam training tool during an exercise session. Students get instant and anonymous feedback concerning their current performance level and at the same time develop a better understanding of the structure and content of the forthcoming exam.

\subsection{What Did Not Work Well and Why?}

Sharing questions does not work well among educational instructors: out of more than 60,000 questions logged in the system, less than $0.3 \%$ are shared with other users of PINGO. We have not fundamentally analyzed this instructor behavior so far, so I can only speculate. My guess is that sharing has to involve some kind of social interaction between instructors, something that PINGO itself does not currently provide.

We further tried to incentivize a group of bachelor students to build up an online repository of student-generated multiple-choice questions after each lecture, for future use as a test bank for exam preparation by all students enrolled on a course. The best questions were supposed to be used in the next lecture via PINGO to initiate a discussion on the fundamental concepts introduced in the previous lecture. It turned out that the students were not generating high quality questions despite intensive personal coaching and provision of guidance material. We figure that, first, the offered grade bonus for participating in this activity may have been too small an incentive relative to the effort involved, and second, that it really is difficult to come up with good questions (see above).

\subsection{Did You Stay with Your New Teaching Approach? What Did You Modify?}

I generally stayed with using PINGO, but I use the didactical options that an ARS like PINGO provides more selectively and in a more nuanced way in my courses now, compared with 3 years ago.
2.8 Do You Have Any Advice for Other Course Instructors?

First, augmenting and enriching teaching with technology needs time - for preparation and in class. While the benefits may seldom be instantly visible, the long-term benefits are rewarding. Second, centering on defined learning outcomes and pedagogy instead of technology is only possible if technology operates failure-free, if it can be integrated seamlessly and is as easy to use as possible for both students and instructors ('no handbook needed'). Third, in large classes, do not expect all students to participate when using an anonymous polling system, even if the smartphone penetration definitely allows them to do so - and also do not expect a sudden eruption of student interaction in a big lecture hall, just by using an ARS.

\subsection{Did You Use a Textbook in Addition} to Educational Technology?

Yes, I am still using a textbook in addition to educational technology in all my introductory courses and also in some more advanced courses. Amongst others, textbooks help to organize the material and maintain a consistent terminology throughout the course. Furthermore, modern textbooks - often offered as ebooks or interactive books - usually serve as a type of integration platform for multimedia content.

Prof. Dr. Dennis Kundisch Paderborn University

\section{Interactive Videos as an Instrument for E-Learning}

\subsection{Introduction and Background}

Today's students - influenced by Web 2.0 and mobile applications - are used to interact with and through media instead of only consuming it. Therefore, the demand for videos in the internet continues to grow. Videos support users' information processing by sequencing information and by reducing the cognitive load. Moreover, learners might get additional concept formation guidance from slow motion, freeze frames, repetitions and the overlay of additional text. The benefits of visual materials can be further increased by introducing interaction in videos similar to hyperlinks in websites.

The technology seems to be extremely useful in the context of e-learning. A multitude of studies has shown that visual material or also visual imagination can be easily and firmly memorized (Metzig and Schuster 2000). Especially since the concept of direct manipulation (Shneiderman 
1983), which is used synonymously with the modern human-machine-interface, the terms interaction and interactivity have gained great importance in scientific literature. Interactivity offers the user miscellaneous possibilities to interfere and to control in the context of computer systems. There are many attempts to define this term, which often consider vaguely the user's active part as well as the variability in the choice of contents. At any rate, it is a common understanding that different levels of interactivity can be distinguished, but there is no consensus about these levels so far. The same happens with the designation of a video as interactive. It is unquestioned that interactivity is hard to categorize into clearly definable classes, but as a first step a minimum set of requirements must be fulfilled in the case of an interactive video:

- The video has to be a real video, which means it has to be a moving picture with audio. It cannot be composed out of a series of animations which only come into action when the user provides an input. The video must be recognizable as a video without the user's interference.

- The video must have more features than start, stop and pause, because these are the main features of a video player.

- In the video there should be at least one sensitive spot with which the user can interact in some way, e.g., by clicking.

Further, research has revealed that interactivity - if it is not understood as random access to information but as a possibility to interfere in a didactic offer - can increase the efficiency of learning programs and thus support the individual learning process (Langbauer et al. 2016). Therefore, the interactivity can be divided into various categories and characterized by the level of interaction, as listed according to Schulmeister (2003):

- Interaction level 1: examine the learning object.

- Interaction level 2: vary the form of representation of the learning object, contemplate different presentation methods.

- Interaction level 3: modify the content of the learning object, choose or calculate other contents.

- Interaction level 4: combination of criteria 2 and 3, vary the form of presentation and modify the content.

- Interaction level 5: construct the learning object by yourself, use editors or simulations.

- Interaction level 6: obtain feedback from the learning object.

This implies that interactivity offers a broad spectrum of opportunities to design interactive, realistic and student centered learning processes, to adjust complex facts, and to apply knowledge in real life situations. Thus, interactivity represents an effective means for the creation of digital learning content and will achieve an even greater importance for e-learning due to its expected power in motivating students and making them interested in the learning subject (Langbauer et al. 2016; Lehner and Langbauer 2015).

\subsection{SIVA Suite - A New Authoring Tool for Interactive Videos Supporting Learning Innovation}

Due to the great potentials of interactive videos and the lack of simple and generally available production tools, a solution for the linkage of videos with interactive auxiliary contents was developed at the University of Passau (Lehner and Siegel 2009; Meixner et al. 2010). The solution is called 'Simple Interactive Video Authoring Suite' (short: SIVA-Suite) and is based on three components: a "producer' as actual authoring tool, a 'player' for displaying and presenting the output of the produced interactive videos for the user, and a 'server' which serves as both a data and exchange platform (see http://www.mirkul.unipassau.de/software/).

The viewer of a traditional video takes a mostly passive role. Traditional videos are linear and cannot provide additional information about objects or scenes. Contrary to linear videos, an interactive video is a digitally enriched form of video materials arranged for an overall concept. It presents additional information beyond the original content. Furthermore, it offers new forms of influence and navigation in the video as well as additional contents.

Detailed and supplemental images, continuative videos, text annotations and interesting audio files can be added to the original video or scenes of the video as additional information. Breaking up the rigid linear structure of a video by cutting it into shots or scenes allows a rearrangement of the video. Therefore the structure of the video is no longer linear. Branching plotlines can be implemented. It is also possible to access shots and scenes by a table of contents, enabling the viewer to watch only relevant parts of the video. A keyword-search completes the navigational potential of an interactive video.

The simplicity and usability of the SIVA Suite enables virtually every content author to produce interactive videos. Outsourcing production to media experts will no longer be necessary; learners themselves may even develop their own content. Due to this flexibility, future connectivity of the tool is guaranteed. New areas of application will become accessible through the plug-in concept.

\subsection{Learning Scenarios and Experiences}

Meanwhile, the system has been tested in several learning and teaching arrangements. For demos of interactive videos 
see, e.g., http://www.mirkul.uni-passau.de/vorarbeiten/ beispielvideos/. Especially in e-learning applications, an interactive video can support more learners by integrating several options adapted to several types of users with different knowledge levels. Short quizzes can be integrated in the content, and associated with different scenes depending of the result obtained by the user.

A comprehensible scenario is training support by means of video analysis. In high-performance sports, recording training sessions and tournaments to analyze them afterwards has become an important measure. This practice helps the trainee to detect his mistakes and prevents him from making them again. Usually the trainee watches the video together with a qualified trainer who talks about it with him at the same time. Very good recordings can also be used later for courses of instruction. Interactive measures can simplify and improve this process. Single recordings can be easily arranged by means of the software to watch them either in chronological order or simultaneously if various perspectives have been filmed. The beholder has the possibility to watch the given sequence but also to jump into other scenes or perspectives. The trainer, who plays the role of an author, can provide single scenes with comments in form of audio files or texts. These comments can be faded in optionally during play-back. Moreover, the author has the possibility to add graphic elements to the video. He can hint at adjustments by means of arrows or lines, for instance. By using colored markings or pop-ups of details, he can attract attention to several features.

Another application is the description of complex objects based on video material. Descriptions of complex objects in conventional training materials like text books or slides often are difficult to understand. This is why nowadays learning contents based on videos are preferred. In short clips, e.g., complex machines are intelligibly explained from diverse perspectives. Interactive elements can support the learning process in an appropriate way. By means of the authoring tools, you can underline specific sections and enrich them with additional videos, animations or textual information. As a result you can easily recognize a clear relation between descriptions and the related area or scene in the video. The visualization of the object helps to understand complex relations, while detailed additional descriptions in the video can be accessed easily whenever necessary.

There are different opinions about the success of e-learning in general (Scholz et al. 2014). Dillon and Gabbard (1998) note that "the benefits gained from hypermedia technology in learning scenarios appear to be very little". However, they add, there is evidence that individual characteristics have an influence on e-learning. The student can only then profit optimally from an e-learning environment, when he or she has the necessary abilities to use e-learning effectively. It has to be concluded that the success of the introduction of interactive videos in e-learning does not only depend on the introduction of the technology, but rather on considering preconditions on the students' side as well as didactical aspects.

In addition to the possibilities of technical implementation, a successful use of e-learning tools like interactive videos demands a new orientation of the teaching and learning attitudes, i.e., by teachers as well as by students. This new orientation covers, simply formulated, the way a teacher organizes his or her classes, his or her understanding of knowledge, and the use of technology in class or within the learning process. For the students, as well, the understanding of knowledge, how he or she handles problems, and the way of learning are affected. These attitudes are called epistemological beliefs. The central subject of a lesson or lecturing in general should be to fully use all the potential of the new media. The popular understanding is that the epistemological attitudes count as the most important factor, which influences its best use (Gruber et al. 2007).

Until now, no specific measurement instrument exists that measures the learning performance or other benefits from interactive videos. However, it can be stated that interactive videos provide the potential to transform traditional teacher-directed instruction into powerful, studentled, inquiry-based learning. They foster transfer of knowledge and collaboration in numerous scenarios.

Prof. Dr. Franz Lehner University of Passau

\section{How We Flipped Our Classroom - Benefits, Challenges and Next Steps}

\subsection{Introduction}

Teaching in higher education is in change and we witness this situation when reflecting our own teaching efforts. A couple of years ago, learning with tablets in large-scale lectures and according integration into learning processes, for example with audience response systems, was our gold standard. By integrating and re-designing lectures (Wegener et al. 2012), we made a major step towards digitization in teaching and also received recognition for our efforts from the government (see https://www.uni-kassel. de/go/bisebs) as well as the Association for Information Systems (see https://aisnet.org/?EduTeachingAward). However, recent developments in pedagogy as well as technology made it possible to go one step further. Approaches such as flipped classrooms and massive open 
online courses (MOOCs) were teaching and learning innovations that are the logical next step in higher education, as educational startups like Coursera or the Singularity University show. Therefore, I will discuss briefly in the next sections how we have implemented a technologydriven flipped classroom approach in large-scale lectures and discuss the benefits and challenges we witnessed, what we have learned with the approach taken, and what thoughts should be taken into account when considering the next steps in higher education.

\subsection{Implementing a Flipped Classroom in University Teaching}

Since large-scale lectures in universities, such as introductory lectures, are typically crowded and do not offer many possibilities for rich interaction between the lecturer and students, we sought for a way to use in-class time more productively. Such a possibility was offered by the flipped classroom concept (Lehmann et al. 2015). This concept refers to the process of acquiring knowledge outside the classroom when not in direct contact with a lecturer. Students are required to teach themselves basic knowledge, and the classroom time focuses on mastery activities. Outside of class, learners have access to online videos and additional learning material to study the subject matter on their own. In class, learners concentrate on understanding, applying, and analyzing the subject matter they previously studied with learner-centered activities that enhance critical thinking or problem-solving skills.

However, just developing and changing the pedagogical concept is the rather easy part and does not take a holistic perspective into account. Therefore, we developed according learning materials including the revision of a textbook (Leimeister 2015), produced videos and corresponding presentation slides, developed student tutorials and quizzes for every learning goal that could be assessed automatically in a learning management system (Janson et al. 2017) as well as assignments such as peer assessments (Lehmann et al. 2016) to also assess higher learning goals, which are often not considered in large-scale lectures.

\subsection{Benefits, Challenges and Lessons Learned}

First, it is rather obvious and a natural corollary that the major benefit was the constant interaction with students over the semester. Previously, we just got a little glimpse of how our students learned during the semester. But now, we have very distinct impressions of our students including information concerning quiz and assignment results, which learning content is actually used and how prepared learners are in class. This holds also true for students who are now constantly provided with formative assessments and our performance expectation during the semester. Second, it gives us room to be more productive in class and the opportunity to fundamentally change the role of the lecturer from 'sage on the stage' to 'guide on the side' (King 1993). Third, by producing mostly modular learning content, we are easily able keep our learning content up to date, which is quite important in dynamic disciplines such as ours. Fourth, by keeping modularity for the lecture design in mind, it is also possible to adopt and adapt specific teaching approaches such as peer assessments in other lectures. Using peer assessment in which students have two roles: content creator and reviewer, we create twofold value for the learner. On the one hand, the student intensively engages with the course content through carrying out the assignment. On the other hand, through reviewing the assignments of fellow students, the students train their ability to provide feedback.

However, it all comes with certain challenges and drawbacks. Taking a step back again, the initial content creation was a very time-consuming process, especially the video creation. It was an important lesson for us not to underestimate the amount of time it needs to produce digitized learning contents. In addition, it did not pay off first. Students were often disappointed and expressed in the evaluation that such a new teaching concept comes with more responsibilities. Undergraduate students are often accustomed to the typical 'sage on the stage' and are fairly hard to convince that self-regulated preparation of learning content during the semester is necessary. For us, after the first courses, it was therefore very important to take into account such drawbacks by better explaining why we follow such an approach and how students will profit from it in the long run, and by intensely supporting especially the early phases in the learning process, in order not to lose students on their way. However, we stayed with the new approach and tackled the challenges on a constant basis, also by transferring the logic of designing the learning processes and environment to other courses for example in graduate or executive education.

\subsection{What to Do Next?}

From this perspective, the opportunities of technology in higher education are there and have to be considered. First, if students use more and more technology in their learning processes, learning analytics might show great potential to support and guide students more individually and, thus, to increase competency development on an individual basis. However, according to personal experiences, legal questions remain concerning data related to the individual, such as quiz scores, which are often not accessible for lecturers. Second, due to the increasing amount of students per 
lecturer, new innovative ways need to be researched, in which lecturers can provide students automatic computerbased feedback. When taking our teaching innovation with a flipped classroom into account, it would also be possible to convert this approach to a MOOC on one of the wellknown platforms. Therefore, digitized higher education is in the area of conflict between generating revenues as a business model on MOOC platforms (Wulf et al. 2014) and enabling open education for everybody. Third and connected with the latter, higher education and politics should take a very close look at the debate over open educational resources, which could be also a major driver of technology in teaching and further the process that lecturers can guide and interact with their students, instead of producing new content. This might offer interesting pathways for higher education. As Alavi and Leidner (2001) pointed out already more than 15 years ago: There is a "dramatic increase in the development of technology-based teaching and learning", and it is picking up and gaining momentum. Offers from players like Udacity show that there is more and more pressure to improve learning success and that this is more important than ever.

Prof. Dr. Jan Marco Leimeister University of St. Gallen \& University of Kassel

\section{The ERP Challenge: An Integrated E-Learning Platform for Teaching ERP Systems}

\subsection{What Was Your Teaching Innovation? What Did You Change Compared to Your Earlier Teaching Approach? What Are Your Experiences with Interlinking Teaching Strategies and Tools?}

\subsubsection{Basic Idea}

The teaching innovation (named 'ERP Challenge') is a hybrid e-learning module for use in a combined lecture class/exercise on ERP Systems. The core consists of a selfdeveloped Web application (an extension of the Open Source CMS Drupal). The ERP course module consists of a class on ERP Systems (theory component) and a complementary exercise (practical) component. Prior to the introduction of the ERP Challenge, these two components were largely independent. The lecture class provided the basic theory, methods, concepts and terminology of ERP systems, the exercise part provided an environment for practical work with an ERP system. This setup presented two challenges: (1) The teaching instructors are mostly Ph.D. students who teach the exercise a maximum of 3-5 times before they finish their Ph.D. thesis. ERP systems are complex software systems that require a high degree of familiarity, so there was the need to constantly acquire and train skilled teaching instructors. (2) The students perform practical tasks in the ERP system, which have to be graded, and feedback must be provided. The ERP class at the University in Koblenz is a fairly large class with 120-160 students taking the course each time it is offered. Grading the submissions and providing individual feedback was a huge effort for the teaching instructors and their tutors (student helpers). (3) The tasks to be performed by the students were rather theoretical and stand-alone. There was room for improvement regarding relevance to practice and linking the tasks to real-world processes in a company.

The teaching innovation addresses these three issues. The ERP Challenge is a software-assisted business simulation game based on a case study of an existing organization that provides the necessary business context, rules and processes. The software platform of the ERP Challenge was developed to provide students with practical skills in ERP system use. The software platform is composed of three different systems: (1) The actual ERP system (MS Dynamics NAV), (2) a self developed e-learning system based on the Open Source CMS Drupal, and (3) the University's collaboration environment (UniConnect). The ERP system and the e-learning system are technically integrated.

\subsubsection{Teaching Strategy}

The teaching approach facilitated by the ERP Challenge provides a seamless combination of theoretical knowledge and practical experience with ERP Systems. The students are presented with individual assignments, which makes sure that every student participates in, and benefits from the course experience. The grading of student tasks is performed using an autograder. There is an additional gamification component: the students' results are ranked (anonymously) so that the participants can see their performance compared to the performance of their peers. There has been much discussion about MOOCs, which are courses geared at large numbers of participants (de Waard et al. 2011). The ERP Challenge uses elements from MOOCs but is a SPOC (a Small Private Online Course) (Fox 2013). The effect of the ERP Challenge is that it provides an innovative and motivating way to work with an ERP system and that it eases the lecturer's administrative work for the course.

\subsubsection{Technical Implementation}

The key feature of the ERP Challenge is the technical integration between the e-learning platform and the ERP system. The e-learning platform has direct access to the database of Microsoft Dynamics NAV. All servers are hosted on the University's IT infrastructure. The technical 


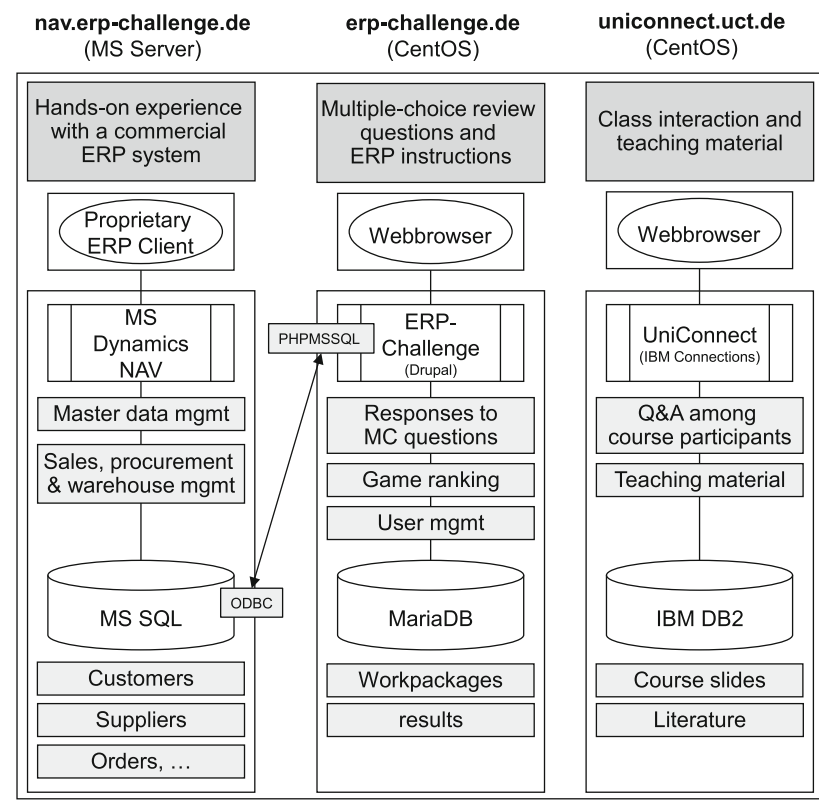

Fig. 1 The three software systems for the ERP challenge

architecture is designed in such a way that it could be offered as a hosted service to other universities.

Figure 1 provides an overview of the technical architecture of the ERP Challenge with its three software systems: erp-challenge.de, nav.erp-challenge.de, uniconnect.uct.de

\subsection{What Did You Perceive As Main Challenges}

with Implementing the New Course Design? Did

You Use Any Support from Instructional Designers

or Did You Approach the Problem on Your Own?

There were two challenges for the development of the ERP Challenge: (1) Developing the concept for the business simulation ('the case study'), and (2) the technical integration between the ERP system and the e-learning platform to enable the autograder. The case study was developed with the help of an existing company, a regional furniture company. The description of the case and the diagrams for the business processes were developed with the help of this company's CTO. The technical integration was developed by a team of students within the scope of a course assignment (Forschungspraktikum). An ongoing challenge is keeping the software components of the ERP Challenge up to date with the constantly changing software releases (of the ERP System and the CMS alike).

\subsection{What Did Work Well and Why? What Did Not Work Well and Why?}

Internal perspective (= success): the ERP Challenge has been in place for 3 years and it has successfully addressed the issues described above. It has made the process of marking the students' assignments and providing feedback very easy and efficient. Three consecutive surveys at the end of the semester showed that the students like the ERP Challenge and the majority reported that they would like to see similar e-learning approaches in other subjects (Schwade and Schubert 2016).

External perspective (= failure): the ERP Challenge was developed with the idea that it could be offered to other Universities or teaching institutions as a hosted solution. After presentations at academic conferences and discussions with potential software providers, it became clear that there is great demand for such an e-learning tool on the University side but that no organization is willing to bear the cost of development and maintenance.

\subsection{Did You Stay with Your New Teaching Approach? What Did You Modify?}

The ERP Challenge has been successfully used for four years now. We have made minor changes to the technology (e.g., when a new version of the ERP System became available) but the simulation game and the processes and students' tasks stayed the same. The ERP Challenge has improved the quality of our ERP education for students and it would be a backward step if we had to return to the old segmented teaching approach.

\subsection{Do You Have Any Advice for Other Course Instructors? Any Lessons Learned? What Blend of Strategies and Tools Do You Think Suits Which Purposes?}

The development of a business simulation game is a lot of work and requires people with enough experiences and skills in the problem domain. Writing the case, developing the business process diagrams and the student tasks and setting the ERP system up with the basic data was time consuming but could probably be done by any experienced ERP lecturer. The technical part, on the other hand, requires profound technical skills in this case of the ERP system and the CMS. This expertise is usually not available in Universities and cannot be developed within the scope of a course assignment. We were fortunate to have a student in the development team who already worked for a software company and was a certified Navision expert.

\subsection{Did You Use a Textbook in Addition} to Educational Technology? Do You Consider Textbooks Are Out of Date? Will Audio and/ or Visual Material Take Over?

We use a textbook for the theoretical part of the course and it is essential for the teaching of basic concepts, theories 
and terminology. It was never meant to be replaced by the e-learning tool but the multiple-choice questions that the students answer in their assignments are based on the content of the textbook and require them to continuously revise the theory during the course of the semester. This has led to much better exam results than before the introduction of the ERP Challenge.

A more detailed account on the development of and the experiences with the ERP Challenge can be found in (Schwade and Schubert 2018).

Prof. Dr. Petra Schubert University of Koblenz-Landau

\section{References}

Alavi M, Leidner DE (2001) Research commentary: technologymediated learning - a call for greater depth and breadth of research. Inf Syst Res 12(1):1-10. https://doi.org/10.1287/isre. 12.1.1.9720

Beutner M, Kundisch D, Magenheim J, Zoyke A (2014) Support, supervision, feedback and lecturer's role in the use of the classroom response systems PINGO. In: World conference on E-learning, New Orleans, pp 197-204

de Waard I, Koutropoulos A, Keskin NÖ, Abajian SC, Hogue R, Rodriguez CO, Gallagher MS (2011) Exploring the MOOC format as a pedagogical approach for mLearning. In: World conference on mobile and contextual learning, Beijing, pp 138-145

Dillon A, Gabbard R (1998) Hypermedia as an educational technology. A review of the quantitative research literature on learner comprehension, control, and style. Rev Educ Res 68(3):322-349

Dufresne R, Gerace W, Leonard W, Mestre J, Wenk L (1996) Classtalk: a classroom communication system for active learning. J Comput Higher Educ 7(2):3-47. https://doi.org/10.1007/ BF02948592

Fox A (2013) From MOOCs to SPOCs. Commun ACM 56(12):38-40. https://doi.org/10.1145/2535918

Gruber H, Harteis C, Hasanbegovic J, Lehner F (2007) Über die Rolle epistemischer Überzeugungen für die Gestaltung von E-Learning-Eine empirische Studie bei Hochschul-Lehrenden. In: Breitner M, Bruns B, Lehner F (eds) Neue Trends im E-Learning-Aspekte der Betriebswirtschaftslehre und Informatik. Physica, Heidelberg, pp 123-132

Janson A, Söllner M, Leimeister JM (2017) Individual appropriation of learning management systems-antecedents and consequences. AIS Trans Hum Comput Interact 9(3):173-201

King A (1993) From sage on the stage to guide on the side. Coll Teach 41(1):30-35. https://doi.org/10.1080/87567555.1993. 9926781

Kundisch D, Herrmann P, Whittaker M, Beutner M, Fels G, Magenheim J, Reinhardt W, Sievers M, Zoyke A (2012) Designing a web-based application to support peer instruction for very large groups. In: International conference on information systems, Orlando, pp 1-12

Kundisch D, Herrmann P, Whittaker M, Neumann J, Magenheim J, Reinhardt W, Beutner M, Zoyke A (2013a) Designing a webbased classroom response system. In: International conference on design science research in information systems, Helsinki. Springer, Heidelberg, pp 425-431
Kundisch D, Magenheim J, Beutner M, Herrmann P, Reinhardt W, Zoyke A (2013b) Classroom response systems. InformatikSpektrum 36(4):389-393. https://doi.org/10.1007/s00287-0130713-0

Langbauer M, Amende N, Lehner F (2016) Zur Rolle von Interaktivität bei interaktiven Videos als Lernmedium-Eine explorative Studie. In: Nissen V, Stelzer D, Straßburger S, Fischer D (eds) Multikonferenz Wirtschaftsinformatik, vol III, Ilmenau, pp 1823-1834

Lehmann K, Oeste S, Janson A, Söllner M, Leimeister JM (2015) Flipping the classroom-IT-unterstützte Lerneraktivierung zur Verbesserung des Lernerfolges einer universitären Massenlehrveranstaltung. HMD Praxis der Wirtschaftsinformatik 52(1):81-95. https://doi.org/10.1365/s40702-014-0102-4

Lehmann K, Söllner M, Leimeister JM (2016) Design and evaluation of an IT-based peer assessment to increase learner performance in large-scale lectures. In: International conference on information systems, Dublin, pp 1-21

Lehner F, Langbauer M (2015) An interactive video system for learning and knowledge management. In: Hinkelmann K, Thönssen B (eds) Proceedings of the 3rd international conference on enterprise systems, Basel. CPS/IEEE, Los Alamitos, pp 55-65. https://doi.org/10.1109/es.2015.13

Lehner F, Siegel B (2009) E-Learning mit interaktiven VideosPrototypisches Autorensystem und Bewertung von Anwendungsszenarien. In: Schwill A, Apostolopoulos N (eds): Lernen im digitalen Zeitalter. GI Lecture Notes in Informatics, vol P-153. Bonn, pp 43-54

Leimeister JM (2015) Einführung in die Wirtschaftsinformatik, 12th edn. Springer Gabler, Heidelberg

Mazur E (1997) Peer instruction: a user's manual. Prentice Hall, Upper Saddle River

Meixner B, Siegel B, Hölbling G, Lehner F, Kosch H (2010) SIVA Suite. Authoring system and player for interactive non-linear videos. In: Proceedings of the international conference on Multimedia (MM 2010), Firenze. ACM, New York, pp 1563-1566

Metzig W, Schuster M (2000) Lernen zu lernen. Springer, Heidelberg

Scholz M, Lehner F, Dorner V (2014) A respecification of the DeLone and McLean model to measure the success of an electronic mediated learning system. In: Kundisch D, Suhl L, Beckmann L (eds) Multikonferenz Wirtschaftsinformatik, Paderborn, pp 805-819

Schulmeister R (2003) Lernplattformen für das virtuelle Lernen. Evaluation und Didaktik. Oldenbourg, München

Schwade F, Schubert P (2016) The ERP challenge: an integrated e-learning platform for the teaching of practical ERP skills in universities. Proc Comput Sci 100:147-155. https://doi.org/10. 1016/j.procs.2016.09.134

Schwade F, Schubert P (2018) The ERP challenge: developing an integrated platform and course concept for teaching ERP skills in universities. Int J Hum Cap Inf Technol Prof 9(1):53-69. https:// doi.org/10.4018/IJHCITP.2018010104

Shneiderman B (1983) Direct manipulation. IEEE Trans Comput 16(8):57-69. https://doi.org/10.1109/MC.1983.1654471

Wegener R, Menschner P, Leimeister JM (2012) Design and evaluation of a didactical service blueprinting method for large scale lectures. In: International conference on information systems, Orlando, pp 1-17

Werbach K (2016) Flip flop: the realities of blended teaching. https:// medium.com/@ kwerb/flip-flop-the-realities-of-blended-teach ing-cdecbec628c5. Accessed 12 July 2017

Wulf J, Blohm I, Leimeister JM, Brenner W (2014) Massive open online courses. Bus Inf Syst Eng 6(2):111-114. https://doi.org/ 10.1007/s12599-014-0313-9 